(2) Open Access Full Text Article

ORIGINAL RESEARCH

\title{
Depressive-, Cognitive- or Stroke-Related Risk Factors of Post-Stroke Depression: Which One Could Better Help Clinicians and Patients?
}

\section{Rebecca Perrain (D) ${ }^{1,2}$ \\ David Calvet ${ }^{3-5}$ \\ Vincent Guiraud ${ }^{3-5}$ \\ Lila Mekaoui' \\ Jean-Louis Mas ${ }^{3-5}$ \\ Philip Gorwood 1,2,5 \\ 'GHU Paris Psychiatrie et}

Neurosciences, CMME, Hôpital Sainte-

Anne, Paris, France; ${ }^{2}$ University of Paris,

Paris, France; ${ }^{3} \mathrm{GHU}$ Paris Psychiatrie et

Neurosciences, Department of

Neurology, Hôpital Sainte-Anne, Paris,

France; ${ }^{4}$ University of Paris, FHU

Neurovasc, Paris, France; ${ }^{5}$ Institute of

Psychiatry and Neuroscience of Paris,

INSERMUI 266, Paris, France
Correspondence: Rebecca Perrain Clinique des Maladies Mentales et de l'Encéphale, Sainte-Anne Hospital, GHU Paris- Psychiatrie \& Neurosciences, 100 rue de la Santé 75674 Paris Cedex I4, Paris, France

Tel +33 | 45658364

Fax +33 । 45657656

Email r.perrain@ghu-paris.fr
Purpose: Post-stroke depression (PSD) affects one third of stroke survivors, with multiple severe negative consequences. We aim to assess the weight of four different types of clinical risk factors for PSD.

Patients and Methods: We conducted a prospective cohort study in a stroke centre. After stroke, patients were assessed for cognitive performances, psychiatric standardized questionnaires and socio-demographic features. They were called three months after and assessed for major depressive episode using DSM criteria.

Results: PSD was diagnosed in 8 of the 59 (13.6\%) patients enrolled in the study. After multivariate analysis, only "previous history of depressive episode" remained a significant predictive factor for PSD, the model explaining $19 \%$ of the total variance $(\mathrm{OR}=18.0$; $\mathrm{p}=0.002$ ). Patients with a previous history of depression had a 10-fold increased risk for PSD.

Conclusion: Previous history of depression is confirmed as a strong risk factor for PDS and allow the identification of an at-risk sub-group of patients.

Keywords: post-stroke depression, depression, stroke, risk factors, prevention, cohort

\section{Introduction}

Worldwide, strokes are the second leading cause of death, after cardiovascular diseases. ${ }^{1}$ In France, strokes are the first leading cause of acquired disability in adults, ${ }^{2}$ leading to more quality of life issues when compared to other vascular diseases, such as myocardial infarction. ${ }^{3}$ Post-stroke depression (PSD) is affecting one third of stroke survivors, with negative consequences such as higher mortality ${ }^{4}$ and poor recovery. ${ }^{5}$ The recent "Stroke early management guideline" from the American Heart Association and American Stroke Association, briefly mentioned PSD, with no specific recommendation regarding efficient screening tools, recommended ways to detect the diagnosis or appropriate treatment strategies.

Several reviews identified a set of PSD risk factors, stressing the role of moodrelated factors such as previous history of mood disorder, pathological crying at stroke onset, or family history of depression. ${ }^{4,6-9}$ Socio-demographic factors and global medical factors were also analysed with some of them being identified as PSD predictors. However, results are still discordant. ${ }^{7-9}$

Cognitive status, at the interface between neurologic damages and psychiatric symptoms, was analysed as well. Post-stroke cognitive impairment has been already associated with PSD. ${ }^{4,10-12}$ 
Cognitive impairment is also observed independently during major depressive episodes, ${ }^{13}$ and could be ongoing afterwards. Delayed memory, ${ }^{14}$ executive functions and attentional skills ${ }^{15}$ have been shown to be impaired even after reaching clinical remission. ${ }^{16}$

Executive and attentional dysfunctions are often coupled. Recent findings have shown that attentional dysfunction could be the primum movens of all depressionrelated cognitive impairment. ${ }^{17}$ Other studies suggested that psychomotor retardation could reflect the « burden » of past depression as being correlated with the number of previous depressive episodes. ${ }^{17,18}$

To our knowledge, there is a lack of studies comparing these different risk factors, and among them neurocognitive impairments, assessing their weight in PSD outcome. Some results suggested that depressive-related symptoms were the most predictive item, but cognitive impairment was always assessed in a global way. ${ }^{8}$

We therefore assessed the weight of four different types of risk factors for PSD. We distinguished those related to psychiatric and mood-related morbidity, those depending on non-psychiatric co-morbidities and strokerelated features, the ones related to specific cognitive impairment - at the interface between neurologic damages and psychiatric symptoms - and lastly the generic ones such as socio-demographic features.

\section{Patients and Methods}

We conducted a prospective cohort study with consecutive inclusions in a stroke unit, at Sainte-Anne hospital, Paris.

\section{Inclusion and Exclusion Criteria}

- Inclusion criteria were (1) age over 18, (2) ischemic or haemorrhagic stroke within 14 days of stroke onset confirmed by magnetic resonance imaging or computed tomography scan.

- Exclusion criteria were (1) poor global medical condition precluding an hour participation in assessments, including hemiparesia ( $\mathrm{N}=35,10.9 \%)$, (2) an impossible follow-up, (3) not a fluent French speaker, (4) aphasia with a language National Institute of Health Stroke Score (NIHSS) item $\geq 2$ or a Boston Diagnostic Aphasia Examination $<8$, (5) hemineglect according to the bells test, (6) antidepressant taken at the stroke onset (as studies showed a preventive effect and then a lower rate of PSD with preventive antidepressant treatment), ${ }^{19}$ (7) major depressive episode present at the stroke onset (8) adults under legal protection and pregnancy or breastfeeding. (9) subdural haematoma, subarachnoid haemorrhage, thrombophlebitis and post-chirurgical stroke.

\section{Estimated Sample Size}

We used the 2.19 odds ratio published in our recent metaanalysis on risk factors associated with PSD regarding "previous history of depression" (the most informative marker), ${ }^{8}$ and a PSD prevalence of $17.7 \%$ for PSD according to another recent meta-analysis ${ }^{7}$ to compute estimated sample size. We estimated that 76 patients were needed to detect a significant role of such risk factors at the end of the cohort, with a risk of $5 \%$ and a power of $90 \%$. As the tests demand different skills, we estimated on a preliminary test sample that one patient out of four would roughly be able to be finally tested, raising the number of patients to be included to 304 .

\section{Demographic Data}

The following demographic data were assessed: age, gender, profession, school level, marital status.

\section{Clinical Assessment}

Data collection and clinical assessment occurred within 14 days of stroke onset, from patient bedside.

1. Stroke characteristics: were assessed including lesion side (right, left, bilateral, median) and stroke severity with the NIHSS. ${ }^{20}$

2. Cognitive tasks: were performed directly from patient bedside, and included the $\mathrm{d} 2$ test (sustained and selective attention), ${ }^{21}$ the Dubois's 5 words test (verbal memory), ${ }^{22}$ the clock drawing test (executive functions, spatial organisation), ${ }^{23}$ and the digit span trial (working memory, verbal memory). ${ }^{24}$ The test description is available in Supplemental Materials.

3. Psychiatric assessment: included the screening of actual and past depressive episodes with a semistructured interview (Mini International Neuropsychiatric Interview, MINI-depression, Fifth edition), depressive symptoms being assessed with the Beck Depression Inventory. ${ }^{25}$ Patients were asked for other past psychiatric history (psychiatric care, treatments). Patients also filled-in the Clinical Global Impression and the Standardised Assessment of Personality Abbreviated Scale (SAPAS), a questionnaire of 8 questions to detect 
personality disorder. Score $\geq 3$ indicate a personality disorder. ${ }^{26}$ Alcohol Use Disorders Identification Test (AUDIT-C) was completed: the threshold value is 5 for men and 4 for women. ${ }^{27}$ Heavy Smoking Index was completed to detect tobacco use disorder (threshold value of 2 ). ${ }^{28}$

Three months after the first visit, all patients were called by a psychiatrist and assessed for depression using DSM criteria with MINI-depression. The single assessment of depression after 3 months is based on a previous work, showing that $85 \%$ of PSD occurred in the three months following stroke. ${ }^{29}$

This study was conducted in accordance with the Declaration of Helsinki and was approved by the French National Ethics Committee called "Comité de Protection des Personnes Sud-Méditerranée II" which reference number is $217 \mathrm{R} 15$. The identification number of the protocol was 2017-A00339-44. All patients gave written informed consent prior to participation. All data were recorded anonymously. This study was registered on clinicaltrials. gov (NTC04008719).

\section{Statistical Analyses}

Student $t$-test was used to compare continuous variables and $\chi^{2}$ test to compare categorical variables. Fisher's exact test was used when minimum expected count was not obtained. Initial data were analysed to study correlation between variables: Pearson correlation was used. When variables were not normally distributed, Spearman test was used. Logistic regression was performed to detect in a multivariate way which parameters were predictive of PSD. For all tests, the threshold of significance was set at $\mathrm{p} \leq 0.05$.

Positive Predictive Value (PPV) and Negative Predictive Value (NPV) of the confirmed predictive factors were calculated. Positive predictive value (PPV) is the proportion of patients with positive predictors that will have PSD $(\mathrm{PPV}=$ True Positives/[True Positives + False Positive]), and the negative predictive value (NPV) is the proportion of patients with negative predictors that will not have PSD (NPV $=$ True Negatives/[True Negatives + False Negatives]).

All statistical analyses were performed with IBM SPSS Statistics for windows, version 23.0. Armonk, NY:IBM Corp.

\section{Results}

Among 321 consecutive stroke patients screened between May 2017 and October 2017, 59 were finally included (Figure 1).

\section{Comparison Between Included and Excluded Patients}

There was no difference between the recruited population compared to the others regarding gender. However, the included patients were younger $(\mathrm{p}<0.001)$ with a lower level of severity considering NIHSS $(p<0.001)$.

\section{Sample Characteristics at Baseline}

Fifty-three (89.8\%) ischaemic strokes were detected, the other being haemorrhagic. Our sample included 21 (35.6\%) women, mean age was 61.9 (SD18.5).

Clinical, imaging characteristics and cognitive tests (Table 1) were not independent, as the NIHSS, working memory, verbal memory and age were correlated with some parameters of the $\mathrm{d} 2$ Test, and the number of past depressive episode was correlated with the percentage of $\mathrm{d} 2$ mistakes.

\section{Prevalence of PSD, Univariate and Multivariate Analyses}

Three months later, two patients could not be assessed. One died (stroke recurrence) and one was lost to follow-up.

PSD was diagnosed in 8 patients $(13.6 \%$ of total sample), all of them being men.

Univariate analysis (Table 2) identified four variables associated with PSD: previous history of depression, previous history of hypertension, tobacco use disorder and male gender, but none of the cognitive test results. We then analysed the associated variables in a logistic regression analysis (Table 3) apart from gender because of the absence of contrast (100\% of PSD being males). Only "previous history of depressive episode" remained a significant predictive factor, the model explaining 19\% of the total variance $(\mathrm{OR}=18.0 ; \mathrm{p}=0.002)$. When considering only male patients, the model explained $33 \%$ of the total variance $(\mathrm{OR}=42.0 ; \mathrm{p}=0.001)$.

Calculated PPV and NPV were, respectively, 46\% and $95 \%$ for previous history of depression. When considering only male patients, we obtained PPV $75 \%$ and NPV $93 \%$. 


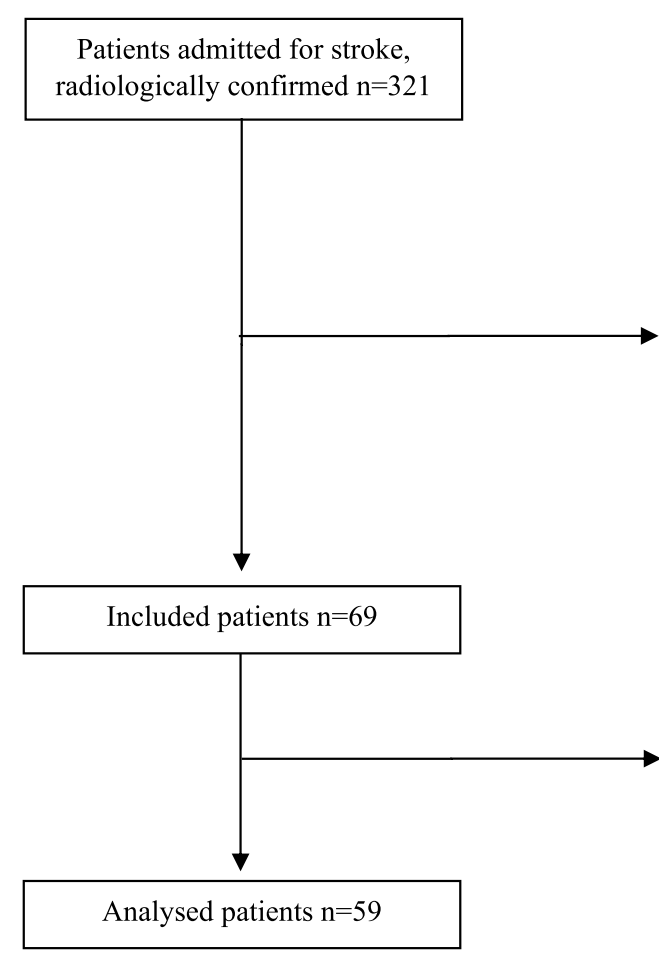

After deadline $(\mathrm{n}=22)$

Discharged $(\mathrm{n}=7)$

Non-datable strokes $(\mathrm{n}=18)$

Depressive episode $(n=3)$

Antidepressant treatment $(\mathrm{n}=40)$

Not a French speaker $(\mathrm{n}=22)$

No social insurance $(\mathrm{n}=2)$

Impossible follow-up $(n=8)$

Unstable neurological or medical status $(n=25)$

Death $(n=11)$

Sensory disease $(n=9)$

Aphasia $\mathrm{NIH} \geq 2(\mathrm{n}=20)$

Hemiparesis $(n=1)$

Participation in another study $(\mathrm{n}=11)$

Hemineglect $(\mathrm{n}=3)$

Severe cognitive impairment $(\mathrm{n}=11)$

Refusal $(n=38)$

Antidepressant treatment $(\mathrm{n}=3)$

Aphasia BDAE $<8(n=2)$

Impossible d2test $(n=4)$

Hemineglect $(\mathrm{n}=1)$

Figure I Flow-chart of the study.

\section{Discussion}

In a study analysing 59 consecutive patients hospitalized in a neurological department specialized in stroke, $14 \%$ developed a PSD three months later. A past history of depression assessed at inclusion was the only predictive factor of future PSD when using a multivariate approach, with a positive predictive value of $46 \%$ and a negative predictive value of $95 \%$. Patients with a previous history of depression had indeed a 10-fold increased risk for PSD. Contrary to our initial hypothesis, no cognitive test performed at the acute period of the stroke was predictive of later PSD.

Patients included in our study were significantly younger and clinically less severe (considering NIHSS) than the rest of the sample. This is explainable as aphasia and hemiparesia were exclusion criteria and are distinct NIHSS items. We assume that it is a selection bias, limiting the generalisation of our results and narrowing its predictive value to patients that are questionable.

In our sample, depression prevalence three months after stroke is $14 \%$, contrasting with the $30 \%$ described in previous studies, ${ }^{4,29}$ but close to a recent meta-analysis that found a pooled prevalence of PSD of $17.7 \% .^{7}$ Our strict DSM assessment avoided over-estimation, but our method excluded aphasic and clinically instable patients, leading indeed to younger, more professionally active patients; therefore, to patients with a lower risk of developing PSD. Moreover, we chose a single assessment of PSD after 3 months whereas other studies frequently rely on a follow-up of 6 months. ${ }^{6}$

We aimed at identifying predictive factors for PSD and after logistic regression, only the item "previous history of depression" remained relevant. The fact that no cognitive test was associated with PSD, could be due to the small sample size leading to a lack of statistical power as an association between cognitive impairment and PSD has been already detected. ${ }^{4}$ On the other hand, these studies assessed cognitive functions in a global way that did not allow specific predictive features. ${ }^{30,31}$

Previous history of depression is a simple feature and can be accurately assessed with brief semi-structured interview, such as the MINI. Our results stress the need of a systematic interview of patients with stroke, at the acute phase, to screen and detect unnoticed past depressive episodes. Previous history of depressive episode is a wellknown risk factor for depressive recurrence. ${ }^{32}$ Genetic factors as polymorphisms of serotonin transporters confer vulnerability to depression and have been identified as risk 
Table I Sample Characteristics of 59 Patients Hospitalized for a Stroke. There Was No Missing Value

\begin{tabular}{|c|c|c|c|c|c|}
\hline $\begin{array}{l}\text { Demographic } \\
\text { Characteristics }\end{array}$ & $\begin{array}{l}\text { n (\%) or Mean } \\
\quad \pm \text { SD }\end{array}$ & $\begin{array}{l}\text { Clinical } \\
\text { Characteristics }\end{array}$ & $\begin{array}{l}\text { n (\%) or Mean } \\
\quad \pm \text { SD }\end{array}$ & $\begin{array}{l}\text { Medical History Previous } \\
\text { History of }\end{array}$ & $\begin{array}{l}\text { n (\%) or Mean } \\
\pm \text { SD }\end{array}$ \\
\hline Age & $61.7 \pm 18.3$ & BDI & $8.4 \pm 5.8$ & Depression & $13(22.0)$ \\
\hline Women & $21(35.6)$ & $\begin{array}{l}\text { Depressed duration } \\
\text { (months) }\end{array}$ & $2.4 \pm 6.5$ & Bipolar disorder & $0(0)$ \\
\hline Profession (Yes) & $29(49.2)$ & SAPAS & $17(28.8)$ & Anxiety disorder & $0(0)$ \\
\hline School level & & Clock test & $27.2 \pm 3.3$ & Schizophrenia & $0(0)$ \\
\hline Primary & $3(5.1)$ & $\begin{array}{l}\text { Verbal memory } \\
\text { (Dubois's) }\end{array}$ & $9.9 \pm 0.5$ & Substance use disorder & I (I.7) \\
\hline Secondary & $17(28.8)$ & $\begin{array}{l}\text { Auditive memory } \\
\text { (DSF) }\end{array}$ & $8.7 \pm 1.7$ & Suicide attempt & I (I.7) \\
\hline Hight school degree & $5(8.5)$ & $\begin{array}{l}\text { Working memory } \\
\text { (DSB) }\end{array}$ & $5.6 \pm 2.2$ & Stroke & $7(11.9)$ \\
\hline $\begin{array}{l}\text { Bachelor level (Ist, 2nd, } \\
\text { 3rd year) }\end{array}$ & $9(15.3)$ & NIHSS & $2.3 \pm 5.3$ & Hypertension & $27(45.8)$ \\
\hline $\begin{array}{l}\text { Master level (Ist, } \\
\text { 2nd year) }\end{array}$ & $16(27.1)$ & Ischaemic stroke & $53(89.8)$ & Myocardial infarction & $2(3.4)$ \\
\hline$>$ Master level & $9(15.3)$ & Stroke side & & Diabetes & $9(15.3)$ \\
\hline Marital/living status & & Right & $25(42.4)$ & Alzheimer & $0(0)$ \\
\hline Single & $9(15.3)$ & Left & $26(44.1)$ & Parkinson & $0(0)$ \\
\hline Couple & $4(6.8)$ & Bilateral & $2(3.4)$ & & \\
\hline Cohabitation & I (I.7) & Median & $6(10.2)$ & & \\
\hline Married & $30(50.8)$ & & & & \\
\hline Divorced & $8(13.6)$ & & & & \\
\hline Widowed & 7 (II.9) & & & & \\
\hline
\end{tabular}

Abbreviations: SD, Standard Deviation; BDI, Beck Depression Inventory; SAPAS, Standardized Assessment of Personality - Abbreviated Scale; Duboi's, Duboi's 5 words; DSF, digit span forwards; DSB, digit span backwards; NIHSS, National Institute of Health Stroke Score.

factors for post-stroke depression. ${ }^{4,33}$ Stroke could be considered as a biopsychosocial stress leading to recurrence. Another hypothesis of possible mechanism of the impact of previous history of depressive episode on PSD, is that previous depressive episodes have consequences like a possible cognitive scar that could lead to recurrence. ${ }^{15}$

Some limits should be stressed in the present study. First, the recruitment was monocentric and hospitalbased, limiting results generalizability. However, this approach allows a complete recruitment of all stroke patients comparing with other studies in rehabilitation units and a relatively low attrition rate was observed in our sample. Second, we excluded patients with severe stroke, therefore all patients with significant aphasia, which creates a bias and explains the high drop-out between patients screening and inclusion. However, as language is needed to obtain patients' agreement and is required to understand the different cognitive tests, such bias is difficult to avoid. Anyhow, it means that the conclusions drawn from this study have to be limited to patients able to communicate and to perform cognitive tests. Third, the sample size remains relatively small and may have lowered statistical power. Finally, all depressed patients were men, which constitutes a sample bias and is strikingly not in line with previous reviews. 
Table 2 Univariate Approach of Factors Describing a Sample of 59 Patients with Stroke, According to the Development (or Not) of a Post-Stroke Depression 3 Months Later

\begin{tabular}{|c|c|c|c|c|c|c|c|c|c|c|c|c|}
\hline \multirow[t]{3}{*}{ Factors } & \multicolumn{8}{|c|}{ Post-Stroke Depression } & \multicolumn{4}{|c|}{ Statistics } \\
\hline & \multirow{2}{*}{$\begin{array}{l}\text { No } \\
\text { Mean }\end{array}$} & \multirow[b]{2}{*}{ SD } & \multirow[b]{2}{*}{$\mathbf{n}$} & \multirow[b]{2}{*}{$\%$} & \multirow{2}{*}{$\begin{array}{l}\text { Yes } \\
\text { Mean }\end{array}$} & \multirow[b]{2}{*}{ SD } & \multirow[b]{2}{*}{$\mathbf{n}$} & \multirow[b]{2}{*}{$\%$} & \multirow[b]{2}{*}{$\chi^{2}$} & \multirow[b]{2}{*}{$\mathbf{t}$} & \multirow[b]{2}{*}{$d f$} & \multirow[b]{2}{*}{ p-value } \\
\hline & & & & & & & & & & & & \\
\hline \multicolumn{13}{|l|}{ Depressive-related } \\
\hline Previous history of depression & & & 7 & 14.3 & & & 6 & 75.0 & 14.40 & & I & $<0.001$ \\
\hline Depressive symptoms (BDI) & 7.73 & 4.95 & & & 11.38 & 9.40 & & & & -1.07 & 7.65 & 0.32 \\
\hline Time duration of depression (months) & 1.49 & 5.64 & & & 8.63 & 8.77 & & & & -2.23 & 7.97 & 0.06 \\
\hline Number of past episodes & 0.12 & 0.33 & & & 0.88 & 0.99 & & & & -2.13 & 7.26 & 0.07 \\
\hline Tobacco consumption score & 0.16 & 0.90 & & & 1.38 & 2.26 & & & & -1.50 & 7.36 & 0.18 \\
\hline Tobacco use disorder & & & 1 & 2.0 & & & 2 & 25.0 & 7.30 & & 1 & 0.007 \\
\hline Alcohol consumption score & 2.51 & 2.11 & & & 5.38 & 4.10 & & & & -1.93 & 7.62 & 0.09 \\
\hline Alcohol use disorder & & & 11 & 22.4 & & & 4 & 50.0 & 2.70 & & 1 & 0.10 \\
\hline Personality disorder (SAPAS) & & & 14 & 28.6 & & & 3 & 37.5 & 0.26 & & 1 & 0.61 \\
\hline Previous history of suicide attempt & & & 0 & 0.0 & & & I & 12.5 & 6,23 & & 1 & 0.14 \\
\hline \multicolumn{13}{|l|}{ Non-psychiatric \& stroke-related } \\
\hline CGI & 2.82 & 1.11 & & & 2.88 & 1.46 & & & & -0.13 & 55 & 0.90 \\
\hline Stroke type & & & 1 & 12.5 & & & 5 & 10.2 & 0.04 & & 1 & 0.84 \\
\hline Lesion side Right & & & 20 & 40.82 & & & 3 & 37.5 & 4.89 & & 3 & 0.18 \\
\hline Left & & & 24 & 48.98 & & & 2 & 25.0 & & & & \\
\hline Bilateral & & & 1 & 2.04 & & & $\mathrm{I}$ & 12.5 & & & & \\
\hline Median & & & 4 & 8.16 & & & 2 & 25.0 & & & & \\
\hline NIHSS & 1.94 & 5.52 & & & 2.25 & 2.61 & & & & -0.16 & 55 & 0.88 \\
\hline Previous history of stroke & & & 5 & 10.2 & & & I & 12.5 & 0.04 & & 1 & 0.84 \\
\hline Previous history of hypertension & & & 20 & 40.8 & & & 7 & 87.5 & 6.01 & & I & 0.021 \\
\hline Previous history of diabetes & & & 8 & 16.3 & & & I & 12.5 & 0.08 & & 1 & 1.00 \\
\hline Previous history of myocardial infarction & & & 1 & 2.0 & & & I & 12.5 & 2.22 & & 1 & 0.14 \\
\hline \multicolumn{13}{|l|}{ Cognitive-related } \\
\hline Spatial organisation (clock test) & 27.00 & 3.37 & & & 29.25 & 1.39 & & & & -1.85 & 55 & 0.07 \\
\hline Verbal memory (Dubois's 5 words) & 9.86 & 0.54 & & & 10.00 & 0.00 & & & & -0.74 & 55 & 0.46 \\
\hline Verbal memory (DSF) & 8.76 & 1.58 & & & 9.13 & 1.96 & & & & -0.60 & 55 & 0.55 \\
\hline Working memory (DSB) & 5.61 & 2.62 & & & 5.88 & 1.46 & & & & -0.32 & 55 & 0.75 \\
\hline \multicolumn{13}{|l|}{ Attention ( $\mathrm{d} 2$ test) } \\
\hline GZ (number of marked items) & 482.63 & 762.68 & & & 414.13 & 63.14 & & & & 0.25 & 55 & 0.80 \\
\hline FI (number of omission mistakes) & 16.20 & 15.82 & & & 24.50 & 18.94 & & & & -1.34 & 55 & 0.19 \\
\hline $\begin{array}{l}\text { F2 (number of commission/confusion } \\
\text { mistakes) }\end{array}$ & 0.94 & 2.00 & & & 1.38 & 1.69 & & & & -0.58 & 55 & 0.56 \\
\hline F total (total number of mistakes) & 17.14 & 16.09 & & & 25.88 & 18.94 & & & & -1.39 & 55 & 0.17 \\
\hline BR (number of correctly marked items) & 145.96 & 48.18 & & & 148.63 & 12.28 & & & & -0.16 & 55 & 0.88 \\
\hline $\mathrm{KL}(\mathrm{BR}-\mathrm{F} 2)$ & 145.02 & 48.51 & & & 147.25 & 12.89 & & & & -0.13 & 55 & 0.90 \\
\hline \multicolumn{13}{|l|}{ Socio-demographic } \\
\hline Gender (female) & & & 19 & 38.8 & & & 0 & 0.0 & 4.65 & & I & 0.042 \\
\hline Age & 61.41 & 19.33 & & & 62.50 & 7.64 & & & & -0.28 & 25,3 & 0.78 \\
\hline Study level Primary/secondary school & & & 18 & 36.7 & & & I & 12.5 & 4.76 & & 4 & 0.33 \\
\hline High school degree & & & 3 & 6.1 & & & 2 & 25.0 & & & & \\
\hline Bachelor level (Ist, 2nd, 3rd year) & & & 7 & 14.3 & & & 2 & 25.0 & & & & \\
\hline Master level (Ist, 2nd year) & & & 13 & 26.5 & & & 2 & 25.0 & & & & \\
\hline
\end{tabular}

(Continued) 
Table 2 (Continued).

\begin{tabular}{|c|c|c|c|c|c|c|c|c|c|c|c|c|}
\hline \multirow[t]{3}{*}{ Factors } & \multicolumn{8}{|c|}{ Post-Stroke Depression } & \multicolumn{4}{|c|}{ Statistics } \\
\hline & No & & & & Yes & & & & & & \multirow[b]{2}{*}{$d f$} & \multirow[b]{2}{*}{ p-value } \\
\hline & Mean & SD & $\mathbf{n}$ & $\%$ & Mean & SD & $\mathbf{n}$ & $\%$ & $\chi^{2}$ & $\mathbf{t}$ & & \\
\hline$>$ Master level & & & 8 & 16.3 & & & I & 12.5 & & & & \\
\hline Profession (yes) & & & 24 & 49.0 & & & 4 & 50.0 & 0.01 & & I & 0.96 \\
\hline Marital/living status (not alone) & & & 28 & 57.1 & & & 6 & 75.0 & 0.91 & & I & 0.45 \\
\hline
\end{tabular}

Abbreviations: SD, standard deviation; df, degree of freedom; BDI, Beck Depression Inventory; SAPAS, Standardized Assessment of Personality - Abbreviated Scale; CGI, Clinical Global Impression; NIHSS, National Institute of Health Stroke Score; DSF, digit span forwards; DSB, digit span backwards; KL, concentration performance index.

\section{Conclusion}

We confirm the strength of mood-related risk factors for PSD and allow the identification of an at-risk sub-group of patients for whom a specific follow-up monitoring their mood is needed. Further placebo-controlled trials are needed to recommend preventive antidepressant for this sub-group. Many studies are involved in identifying new complex biomarkers, but the fact that a simple clinical factor, such as past depressive episode, is driving the majority of predictive factor in the present study could

Table 3 Logistic Regression

(a) Logistic regression with variables identified in univariate analysis

\begin{tabular}{|c|c|c|c|c|c|c|c|}
\hline \multicolumn{8}{|c|}{ Variables in the Equation } \\
\hline & & B & S.E. & Wald & $d f$ & Sig. & $\operatorname{Exp}(B)$ \\
\hline \multirow[t]{4}{*}{ Step $I^{a}$} & $\begin{array}{l}\text { Previous history of } \\
\text { depression }\end{array}$ & 2.34 & 1.01 & 5.33 & I & 0.02 & 10.37 \\
\hline & Tobacco use disorder & 20.65 & 7122.14 & 0.00 & I & 0.99 & $928,885,813.88$ \\
\hline & $\begin{array}{l}\text { Previous history of } \\
\text { hypertension }\end{array}$ & 19.60 & 7122.14 & 0.00 & I & 0.99 & $324,787,187.14$ \\
\hline & Constant & -21.82 & 7122.14 & 0.00 & 1 & 0.99 & 0.00 \\
\hline
\end{tabular}

${ }^{a}$ Variable(s) entered on step I: Previous history of depression, Tobacco use disorder, Previous history of hypertension. $\operatorname{Exp}(B)=O R$

(b) Logistic regression in all patients, with "previous history of depression"; relevant variable finally identified

Variables in the Equation

\begin{tabular}{|l|l|l|l|l|l|l|l|}
\hline \multicolumn{2}{|c|}{} & B & S.E. & Wald & df & Sig. & Exp(B) \\
\hline \multirow{2}{*}{ Step I } & Previous history of depression & 2.89 & 0.91 & 10.02 & 1 & 0.00 & 18.00 \\
\cline { 2 - 8 } & Constant & -3.05 & 0.72 & 17.70 & 1 & 0.00 & 0.05 \\
\hline
\end{tabular}

${ }^{a}$ Variable(s) entered on step I: Previous history of depression. $\operatorname{Exp}(B)=O R$

(c) Logistic regression in male patients, with "previous history of depression"; relevant variable identified

\section{Variables in the Equation ${ }^{\mathrm{a}}$}

\begin{tabular}{|l|l|l|l|l|l|l|l|}
\hline \multicolumn{2}{|c|}{} & B & E.S & Wald & df & Sig. & Exp(B) \\
\hline \multirow{3}{*}{ Step I } & Previous history of depression & 3.74 & 1.10 & 11.62 & I & 0.00 & 42.00 \\
\cline { 2 - 8 } & Constant & -2.64 & 0.73 & 13.00 & I & 0.00 & 0.07 \\
\hline
\end{tabular}

${ }^{a}$ Gender: male. ${ }^{b}$ Variable(s) entered on step I: Previous history of depression. $\operatorname{Exp}(B)=O R$ 
be considered as a positive result, such factor being relatively easy, quick and costless to assess.

\section{Acknowledgment}

The authors thank neurologists, nurses, neuropsychologist, speech-therapist of the neuro-vascular unit, Sainte-Anne Hospital. Thanks to Amandine Petit, research nurse at the CMME. Thanks to Alexis Dorra for statistical advice. Raw data are available on request by mailing the corresponding author.

\section{Disclosure}

Prof. Dr. Philip Gorwood reports personal fees from Alcediag-Alcen, personal fees from Angelini, during the conduct of the study.

This research did not receive any other specific grant from funding agencies in the public, commercial, or notfor-profit sector.

The authors report no other conflicts of interest in this work.

\section{References}

1. World Health Organization. The top 10 causes of death; 2020. Available from: https://www.who.int/news-room/fact-sheets/detail/ the-top-10-causes-of-death. Accessed April 8, 2021.

2. INSERM. AVC - Accident vasculaire cérébral; 2017. Available from: http://www.inserm.fr/thematiques/neurosciences-sciences-cognitivesneurologie-psychiatrie/dossiers-d-information/avc-accidentvasculaire-cerebral. Accessed April 8, 2021.

3. Bach J-P, Riedel O, Pieper L, et al. Health-related quality of life in patients with a history of myocardial infarction and stroke. Cerebrovasc Dis. 2011;31(1):68-76. doi:10.1159/000319027

4. Robinson RG, Jorge RE. Post-stroke depression: a review. Am J Psychiatry. 2016;173(3):221-231. doi:10.1176/appi.ajp.2015.15030363

5. Matsuzaki S, Hashimoto M, Yuki S, et al. The relationship between post-stroke depression and physical recovery. J Affect Disord. 2015;176:56-60. doi:10.1016/j.jad.2015.01.020

6. Guiraud V, Gallarda T, Calvet D, et al. Depression predictors within six months of ischemic stroke: the DEPRESS Study. Int $J$ Stroke. 2016;11(5):519-525. doi:10.1177/1747493016632257

7. Mitchell AJ, Sheth B, Gill J, et al. Prevalence and predictors of post-stroke mood disorders: a meta-analysis and meta-regression of depression, anxiety and adjustment disorder. Gen Hosp Psychiatry. 2017;47:48-60. doi:10.1016/j.genhosppsych.2017.04.001

8. Perrain R, Mekaoui L, Calvet D, Mas J-L, Gorwood P. A meta-analysis of poststroke depression risk factors comparing depressive-related factors versus others. Int Psychogeriatr. 2020;1-14. doi:10.1017/S1041610219002187

9. Shi Y, Yang D, Zeng Y, Wu W. Risk factors for post-stroke depression: a meta-analysis. Front Aging Neurosci. 2017;9:218. doi:10.3389/fnagi.2017.00218

10. Johnson JL, Minarik PA, Nyström KV, Bautista C, Gorman MJ. Poststroke depression incidence and risk factors: an integrative literature review. J Neurosci Nurs. 2006;38(supplement 1):316-327. doi:10.1097/01376517-200609000-00008

11. Hommel M, Carey L, Jaillard A. Depression: cognition relations after stroke. Int J Stroke. 2015;10(6):893-896. doi:10.1111/ijs.12057
12. Hyndman D, Ashburn A. People with stroke living in the community: attention deficits, balance, ADL ability and falls. Disabil Rehabil. 2003;25(15):817-822. doi:10.1080/0963828031000122221

13. Austin MP, Mitchell P, Goodwin GM. Cognitive deficits in depression: possible implications for functional neuropathology. $\mathrm{Br}$ J Psychiatry. 2001;178(3):200-206. doi:10.1192/bjp.178.3.200

14. Gorwood P, Corruble E, Falissard B, Goodwin GM. Toxic effects of depression on brain function: impairment of delayed recall and the cumulative length of depressive disorder in a large sample of depressed outpatients. Am J Psychiatry. 2008;165(6):731-739. doi:10.1176/appi.ajp.2008.07040574

15. Cléry-Melin M-L, Gorwood P. A simple attention test in the acute phase of a major depressive episode is predictive of later functional remission. Depress Anxiety. 2016. doi:10.1002/da.22575

16. Rock PL, Roiser JP, Riedel WJ, Blackwell AD. Cognitive impairment in depression: a systematic review and meta-analysis. Psychol Med. 2014;44(10):2029-2040. doi:10.1017/S0033291713002535

17. Nilsson J, Thomas AJ, Stevens LH, et al. The interrelationship between attentional and executive deficits in major depressive disorder. Acta Psychiatr Scand. 2016;134(1):73-82. doi:10.1111/ acps. 12570

18. Gorwood P, Richard-Devantoy S, Baylé F, Cléry-Melin ML, CléryMelun ML. Psychomotor retardation is a scar of past depressive episodes, revealed by simple cognitive tests. Eur Neuropsychopharmacol. 2014;24(10):1630-1640. doi:10.1016/j. euroneuro.2014.07.013

19. Robinson RG, Jorge RE, Moser DJ, et al. Escitalopram and problem-solving therapy for prevention of poststroke depression: a randomized controlled trial. JAMA. 2008;299(20):2391-2400. doi:10.1001/jama.299.20.2391

20. Brott T, Adams HP, Olinger CP, et al. Measurements of acute cerebral infarction: a clinical examination scale. Stroke. 1989;20(7):864-870. doi:10.1161/01.STR.20.7.864

21. Brickenkamp R, Zillmer E. The D2 Test of Attention. Hogrefe; 1998.

22. Dubois B, Touchon J, Portet F, et al. ["The 5 words": a simple and sensitive test for the diagnosis of Alzheimer's disease].[Article in French] Presse Med. 2002;31(36):1696-1699.

23. Montani C, Bouati N, Pélissier C, et al. [Scoring and validation of the Clock Face Test in psychometric assessment of elderly subjects]. [Article in French] Encephale. 1997;23(3):194-199.

24. Leung JLM, Lee GTH, Lam YH, Chan RCC, Wu JYM. The use of the digit span test in screening for cognitive impairment in acute medical inpatients. Int Psychogeriatr. 2011;23(10):1569-1574. doi:10.1017/S1041610211000792

25. Aben I, Verhey F, Lousberg R, Lodder J, Honig A. Validity of the beck depression inventory, hospital anxiety and depression scale, SCL-90, and Hamilton depression rating scale as screening instruments for depression in stroke patients. Psychosomatics. 2002;43 (5):386-393. doi:10.1176/appi.psy.43.5.386

26. Moran P, Leese M, Lee T, et al. Standardised Assessment of Personality - Abbreviated Scale (SAPAS): preliminary validation of a brief screen for personality disorder. Br J Psychiatry. 2003;183 (3):228-232. doi:10.1192/bjp.183.3.228

27. Gual A, Segura L, Contel M, Heather N, Colom J. Audit-3 and audit-4: effectiveness of two short forms of the alcohol use disorders identification test. Alcohol Alcohol. 2002;37(6):591-596. doi:10.1093/alcalc/37.6.591

28. Pérez-Ríos M, Santiago-Pérez MI, Alonso B, et al. Fagerstrom test for nicotine dependence vs heavy smoking index in a general population survey. BMC Public Health. 2009;9(1):493. doi:10.1186/14712458-9-493

29. Hackett ML, Pickles K. Part I: frequency of depression after stroke: an updated systematic review and meta-analysis of observational studies. Int J Stroke. 2014;9(8):1017-1025. doi:10.1111/ ijs. 12357 
30. Vermeer J, Rice D, McIntyre A, et al. Correlates of depressive symptoms in individuals attending outpatient stroke clinics. Disabil Rehabil. 2016:1-7. doi:10.3109/09638288.2016.1140837.

31. Hackett ML, Anderson CS. Predictors of depression after stroke: a systematic review of observational studies. Stroke. 2005;36 (10):2296-2301. doi:10.1161/01.STR.0000183622.75135.a4
32. Kessing LV, Andersen PK, Mortensen PB, Bolwig TG. Recurrence in affective disorder. I. Case register study. Br J Psychiatry. 1998;172 (1):23-28. doi:10.1192/bjp.172.1.23

33. Kohen R, Cain KC, Mitchell PH, et al. Association of serotonin transporter gene polymorphisms with post-stroke depression. Arch Gen Psychiatry. 2008;65(11):1296-1302. doi:10.1001/archpsyc.65.11.1296

\section{Publish your work in this journal}

Neuropsychiatric Disease and Treatment is an international, peerreviewed journal of clinical therapeutics and pharmacology focusing on concise rapid reporting of clinical or pre-clinical studies on a range of neuropsychiatric and neurological disorders. This journal is indexed on PubMed Central, the 'PsycINFO' database and CAS, and is the official journal of The International Neuropsychiatric Association (INA). The manuscript management system is completely online and includes a very quick and fair peer-review system, which is all easy to use. Visit http://www.dovepress.com/testimonials.php to read real quotes from published authors.

Submit your manuscript here: https://www.dovepress.com/neuropsychiatric-disease-and-treatment-journal 